\title{
Measuring the healthfulness of food retail stores: variations by store type and neighbourhood deprivation
}

\author{
Christina Black ${ }^{*}$, Georgia Ntani ${ }^{1}$, Hazel Inskip ${ }^{1}$, Cyrus Cooper ${ }^{1,2}$, Steven Cummins ${ }^{3}$, Graham Moon ${ }^{4}$ and Janis Baird ${ }^{1}$
}

\begin{abstract}
Background: The consumer nutrition environment has been conceptualised as in-store environmental factors that influence food shopping habits. More healthful in-store environments could be characterised as those which promote healthful food choices such as selling good quality healthy foods or placing them in prominent locations to prompt purchasing. Research measuring the full-range of in-store environmental factors concurrently is limited.

Purpose: To develop a summary score of 'healthfulness' composed of nine in-store factors that influence food shopping behaviour, and to assess this score by store type and neighbourhood deprivation.

Methods: A cross-sectional survey of 601 retail food stores, including supermarkets, grocery stores and convenience stores, was completed in Hampshire, United Kingdom between July 2010 and June 2011. The survey measured nine variables (variety, price, quality, promotions, shelf placement, store placement, nutrition information, healthier alternatives and single fruit sale) to assess the healthfulness of retail food stores on seven healthy and five less healthy foods that are markers of diet quality. Four steps were completed to create nine individual variable scores and another three to create an overall score of healthfulness for each store.

Results: Analysis of variance showed strong evidence of a difference in overall healthfulness by store type $(p<0.001)$. Large and premium supermarkets offered the most healthful shopping environments for consumers. Discount supermarkets, 'world', convenience and petrol stores offered less healthful environments to consumers however there was variation across the healthfulness spectrum. No relationship between overall healthfulness and neighbourhood deprivation was observed $(p=0.1)$.

Conclusions: A new composite measure of nine variables that can influence food choices was developed to provide an overall assessment of the healthfulness of retail food stores. This composite score could be useful in future research to measure the relationship between main food store and quality of diet, and to evaluate the effects of multi-component food environment interventions.
\end{abstract}

Keywords: Food environment, Consumer nutrition environment, Diet quality, Dietary inequalities

\section{Background}

There is increasing evidence that the food environment is an important determinant of dietary behaviour and obesity [1,2]. With obesity accounting for almost $21 \%$ of health care costs in the US [3] and the UK's NHS spending more than $£ 5$ billion a year on obesity-related health

\footnotetext{
* Correspondence: cb@mrc.soton.ac.uk

'Medical Research Council Lifecourse Epidemiology Unit, University of Southampton, Southampton General Hospital Tremona Road, Southampton SO16 6YD, United Kingdom

Full list of author information is available at the end of the article
}

problems [4], governments are exploring policy options that modify the food environment to make healthier choices easier for consumers $[5,6]$.

Glanz et al. [7] have developed a conceptual model to guide food environment research. The focal points of the model are the four types of food environments: community nutrition environment, consumer nutrition environment, organisational nutrition environment and information environment. The majority of food environment research has focused on the community nutrition environment [1], which measures the number, type, location and accessibility

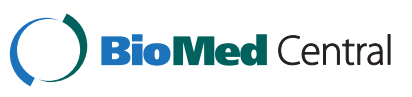


of food sources [7]. Fewer studies have assessed the consumer nutrition environment [8] which considers factors that influence food choice within stores such as availability, price, promotions, placement, variety, quality and nutrition information [7].

Assessment of the consumer nutrition environment in retail food stores is important because of the global convergence of shopping habits away from smaller specialty stores towards stores that stock a wider range of products [9]. Consumer's dietary choices are affected by the products sold, prices charged and promotional strategies used in their main food stores [10]. More healthful food store environments could be defined as those which promote healthful food choices such as selling good quality healthy foods or placing them in prominent locations to prompt purchasing.

A number of tools to assess the consumer nutrition environment have been developed [11,12], with the vast majority for use in the United States (US). Few tools have undergone reliability or validity testing or provide the level of detail required to assess linkages between retail food environments and dietary behaviour $[11,13,14]$. A great proportion of tools measure two in-store factors: availability and price $[11,12,15]$. A smaller number of tools have assessed variety and/or quality of fruit and vegetables [16-18], in-store advertising and/or product placement $[13,19,20]$ or price promotions and nutrition labelling [21].

Some tools enable the creation of a composite score of the in-store environment including the widely used Nutrition Environment Measures Survey-Stores (NEMS-S) [17] and the $C X^{3}$ Food Availability and Marketing Survey [20]; both developed for the US context. The NEMS-S scores and $C X^{3}$ store scores incorporate three in-store factors: availability of healthier products, fruit and vegetable quality, and price or in-store advertising. The Health Responsibility Index was developed to measure the in-store environment of nine supermarkets in the UK [21]. It measured sodium content, nutrition labelling and information, and price promotions on twelve frequently consumed processed products known to be high in sodium. Composite scores incorporating several consumer nutrition environment factors can provide an overall evaluation of the store environment and have been shown to help communities and policy makers in the US identify priority areas and inform interventions [20]. However, no score has included more than three in-store factors or included standardised measures that can be used to statistically assess relationships between diet and in-store environments or monitor relative change in environment over time.

There is a gap in the literature for a comprehensive tool that measures multiple in-store factors concurrently on healthy and less healthy products, particularly outside the US. Such a tool could provide a thorough evaluation of differences in the retail food store environment by store type and neighbourhood deprivation and may identify target sites for interventions.

In the literature, supermarkets are portrayed as offering the healthiest shopping environment for consumers and small convenience stores the poorest $[22,23]$. These broad categories however, cover a heterogeneous group of stores $[10,24]$. In the UK for example, there are four different types of supermarkets that target different consumer groups $[9,10]$ and are likely to offer different shopping environments. Research that excludes the full range of environmental exposures or measures only healthy or less healthy foods may be misrepresenting the food environment within these stores.

Area based differences in the consumer nutrition environment have been observed in the US but no clear trend has been seen in other high income countries [25,26]. In-store assessments based on a limited number of environmental factors and foods may be missing important socio-economic differences. An observation tool that evaluates several environmental exposures of foods commonly used to assess dietary disparities may provide a more complete environmental assessment.

This study addresses a current gap in the literature by developing a comprehensive consumer nutrition environment observational tool to measure the 'healthfulness' of food retail stores in the UK and testing differences by store type and neighbourhood deprivation.

\section{Methods}

\section{Consumer nutrition environment tool development}

A list of all retail food stores and their postcodes in six council boundaries (Southampton, Eastleigh, Fareham, Gosport, Havant, Portsmouth) within Hampshire, UK, was compiled in July and August 2010. Store information was obtained from council Food Safety Registers and on-line business directories (yellow-pages and yell. com). Between July 2010 and June 2011 trained fieldworkers 'ground-truthed' the study area and collected data in 601 of the 606 retail food stores.

A consumer nutrition environment tool was designed to measure nine factors that can affect consumer's food choices. Data on number of varieties, price, promotion, shelf placement and store placement were collected on seven healthy and five less healthy products. In addition, information on the type of nutrition information and availability of a healthier alternative were collected for less healthy products. The quality of two fruits and four vegetables and opportunity for single sale of the two fruits were also measured. Table 1 describes the definitions and measurement scales of the variables included in the tool. Information on fruit and vegetable quality was collected using a published quality indicator [18]. Data on the remaining variables were collected using 
Table 1 Variables measured in the consumer nutrition environment tool

\begin{tabular}{|c|c|c|c|}
\hline & Variable & Definition & Measurement scale \\
\hline I & Variety & $\begin{array}{l}\text { The number of different choices within a product range based on: product flavour, } \\
\text { product size, fair trade/ organic range or no-name/low-cost range }\end{array}$ & Not available, 1, 2, 3, 4, 5+ \\
\hline$\|$ & Price & Price of the cheapest item, $£$ per portion, for each product & Pound sterling per portion \\
\hline III & Promotions & Whether or not the product category was on price promotion & Yes/ no \\
\hline IV & Shelf placement & Where on the shelf the cheapest item for each product was placed & Bottom shelf, other, prominent (eye-level) \\
\hline V & Store placement & Which part of the store the cheapest item for each product was placed & Inconspicuous, noticeable, prominent \\
\hline $\mathrm{Vl}$ & Quality & Level of quality of the two fruit and four vegetables & Poor, medium, good [18] \\
\hline VII & Healthier alternative & Whether or not a healthier option was available for less healthy products & Yes/ no \\
\hline VIII & Nutrition information & The type of nutrition information available on the cheapest item for each product & $\begin{array}{l}\text { None, other }{ }^{\mathrm{a}} \text {, back-of-pack, front \& back } \\
\text { of pack }\end{array}$ \\
\hline IX & Single fruit sale & Whether or not single sale of the two fruit measured was possible & Yes/ no \\
\hline
\end{tabular}

${ }^{a}$ For example recipe card.

novel measures. The tool and survey protocol are available in the Additional file 1. The median time taken to complete the survey across the 601 stores was 11 minutes (IQR: 7, 15).

The 12 food products were: peppers, tomatoes, lettuce, onions, apples, bananas, wholemeal bread, oven chips, sausages, crisps, sugar and white bread. Products were selected because they discriminate between better or poorer dietary patterns, are frequently consumed in England [27] and could be measured in a large survey. The food products selected represent items from short and long food frequency questionnaires (FFQ) used to determine differences in dietary quality among a number of populations including young women, young children and older adults [28-31]. These foods represent the UK Department of Health's dietary recommendations and foods known to contribute to nutrition-related chronic diseases [29].

The level of agreement between fieldworkers was assessed by the Kappa statistic on a sample of 14 stores (large supermarket $(\mathrm{n}=2)$, discount supermarket $(\mathrm{n}=1)$, small supermarket $(\mathrm{n}=4)$, 'world' store $(\mathrm{n}=1)$, convenience store $(n=5)$, petrol store $(n=1))$. The relative consistency of price responses was assessed using the coefficient of variation: the standard deviation of difference divided by the mean (\%). Cronbach's alpha was used to assess the internal consistency of all nine components of the healthfulness score.

\section{Healthfulness score development}

In 2012, a composite score of healthfulness was created for each store surveyed, where each of the nine in-store variables were weighted equally. Seven steps were taken to create the healthfulness scores (Figure 1). Individual scores for each of the nine variables were calculated using steps one to four. All scores were constructed such that higher scores represented more healthful environments. Principal components analysis was applied in an attempt to weight the nine variables however no interpretable patterns were identified.

The process of creating the scores involved: i) converting price measures to pound per portion (using standard portion sizes [32]) and for each store, subtracting the mean healthy item price from the mean less healthy item price, ii), imputing missing values, due to field work error, using the mean value for the variable of that store type, iii) creating summed scores for each store for quality of fruit and vegetables, single fruit sale, nutrition information on and healthier alternative of less healthy products, iv) creating a score for variety, shelf placement, store placement and promotions for each store by calculating the difference between the sum of less healthy scores and the sum of the healthy scores, v) standardising all scores vi) creating a composite score for each store by summing the nine standardised variable scores and dividing by nine, vii) standardising the healthfulness scores (sample mean $=0, \mathrm{SD}=1$ ).

For stores which sold no healthy items the rounded $99^{\text {th }}$ centile of healthy items was imputed as the mean healthy price score. This value represented the time, travel or health costs consumers could bear for healthy products not being available. Stores with no less healthy items were given a mean less healthy price score of zero. Overall, less than $1 \%$ of score components were imputed.

\section{Predictors of healthfulness - store type and neighbourhood deprivation}

Stores were classified into seven categories based on a combination of the Local Authority Enforcement Monitoring System (LAEMS) [33] and previous UK research [34] (Table 2). Store categorisation was confirmed during data collection. A box plot was created to examine the spread of healthfulness scores across the seven store types. To assess differences in store healthfulness and individual in-store factors by store type, analysis of variance was used for normally distributed variables, 


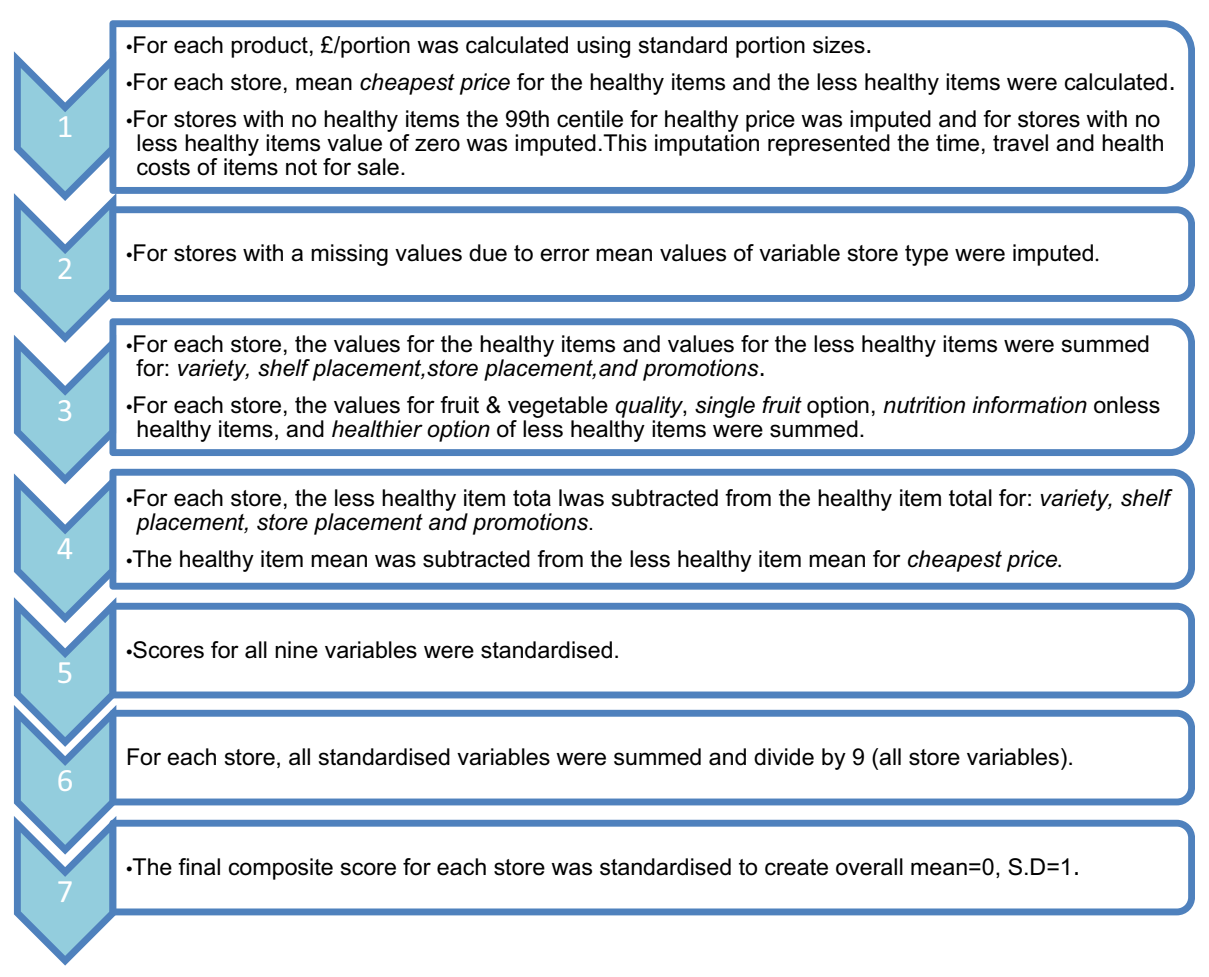

Figure 1 Process to create a composite score of healthfulness for retail food outlets.

Kruskal Wallis test for non-parametric variables, and Chi squared test was used for categorical variables.

Neighbourhood deprivation was measured using the 2007 English Index of Deprivation (ID) income domain. The index of multiple deprivation (IMD) was not applied because of circularity with the access to services domain which included an access to grocery stores measure. The ID is available for Lower Super Output Areas (LSOA), small areas constructed from the 2001 English census that are socially homogenous and have a population size

\section{Table 2 Retail food outlet categorisation system}

\begin{tabular}{|c|c|c|c|}
\hline Code & Store type & Description & Examples \\
\hline \multirow[t]{2}{*}{0} & Premium supermarket & $5+$ manned cash registers & Waitrose, M\&S \\
\hline & & Promoted as offering highest quality goods and service & \\
\hline \multirow[t]{3}{*}{1} & Large supermarket & $5+$ manned cash registers & Tesco, Sainsburys, Asda, Morrisons \\
\hline & & All foods \& many varieties & \\
\hline & & Majority of supermarket share & \\
\hline \multirow[t]{2}{*}{2} & Discount supermarket & $5+$ manned cash registers & Aldi, Lidl, Iceland, Netto, Kwiksave \\
\hline & & Heavily promoted as low price stores & \\
\hline \multirow[t]{2}{*}{3} & Small supermarket & 1-4 manned cash registers & Tesco express, Co-op, Sainsburys local \\
\hline & & Smaller store of known brand name & \\
\hline \multirow[t]{2}{*}{4} & 'World' store & 1-4 manned cash registers & Asian supermarkets, Polish supermarkets, World foods \\
\hline & & Products for specific ethnicities & \\
\hline \multirow[t]{3}{*}{5} & Convenience store & 1-4 manned cash registers & Spar, OneStop, MACE, Independent stores \\
\hline & & Limited number of products & \\
\hline & & Independents \& 'symbols' & \\
\hline \multirow[t]{2}{*}{6} & Petrol station store & Sell petrol/diesel & Shell Select, Tesco petrol station, BP, M\&S \\
\hline & & Includes small supermarkets that sell petrol & \\
\hline
\end{tabular}

\footnotetext{
a 'Symbol' convenience stores are affiliated with a symbol group brand such as OneStop and Spar.
} 
between 1000-1500 residents [35]. Each LSOA in the study area $(n=550)$ was assigned to a quintile of deprivation using the national ranks of 2007 ID income domain [35] $(1=$ most deprived and $5=$ least deprived). Test for trend was performed to examine differences in store healthfulness and individual in-store variables by neighbourhood deprivation. Differences by LSOA rural and urban classification were not assessed because more than $98 \%$ of the study area was classified as urban [36] leaving inadequate variability.

\section{Results}

The response rate for retail food stores in the study was $99 \%(n=601)$. Four convenience and two 'world' stores refused to take part in the study. Table 3 presents the sample by store type and neighbourhood deprivation quintile. The greatest proportion of stores was convenience stores ( $45 \%, \mathrm{n}=268$ ), followed by small supermarkets $(21 \%, \mathrm{n}=127)$; large supermarkets made up $5 \%(\mathrm{n}=32)$ of the sample. Most retail food stores were located in the second most deprived and middle deprivation neighbourhoods (26\%, $\mathrm{n}=154$ and $28 \%, \mathrm{n}=171$ respectively).

Inter-rater reliability revealed almost perfect agreement for single fruit sale, healthier alternative and nutrition information, variety and promotions (kappa $\geq 0.85$ ) [12]. The inter-rater reliability for store placement and shelf placement showed substantial agreement (kappa $\geq 0.73$ ). However, quality of fruit and vegetables showed moderate agreement between field workers (kappa $=0.60)$. The coefficient of variation observed for price was $17 \%$, which showed little variation in price between field workers across all products. The Cronbach's alpha for the standardised components of the healthfulness score was 0.86 .

\section{Predictors of healthfulness score}

Figure 2 indicates that the healthfulness scores were poorer for 'world', convenience, and petrol stores. Discount

Table 3 Store sample by store type and level of neighbourhood deprivation

\begin{tabular}{llllllll}
\hline Store type & $\begin{array}{l}\text { Most } \\
\text { deprived }\end{array}$ & $\mathbf{2}$ & $\mathbf{3}$ & $\mathbf{4}$ & $\begin{array}{l}\text { Least } \\
\text { deprived }\end{array}$ & $\begin{array}{l}\text { Total } \\
\mathbf{n}\end{array}$ & (\%) \\
\hline $\begin{array}{l}\text { Premium } \\
\text { supermarket }\end{array}$ & 1 & 5 & 2 & 2 & 0 & 10 & $(2)$ \\
Large supermarket & 7 & 9 & 8 & 4 & 4 & 32 & $(5)$ \\
$\begin{array}{l}\text { Discount } \\
\text { supermarket }\end{array}$ & 8 & 7 & 12 & 3 & 5 & 35 & $(6)$ \\
Small supermarket & 13 & 31 & 34 & 24 & 25 & 127 & $(21)$ \\
World' store & 17 & 20 & 16 & 6 & 2 & 61 & $(10)$ \\
Convenience store & 44 & 72 & 77 & 39 & 36 & 268 & $(45)$ \\
Petrol station store & 10 & 10 & 22 & 8 & 18 & 68 & $(11)$ \\
Total n & 100 & 154 & 171 & 86 & 90 & 601 & \\
(\%) & $(17)$ & $(26)$ & $(28)$ & $(14)$ & $(15)$ & & $(100)$ \\
\hline
\end{tabular}

supermarkets had the lowest median score of all supermarkets (Table 4) and showed the greatest spread of healthfulness scores for supermarkets. Healthfulness scores were highly positive for premium and large supermarkets, indicating that these stores offered the most healthful environments for consumers. Small supermarkets showed more variation in healthfulness scores than premium and large supermarkets, though scores remained predominantly above zero suggesting better than average healthfulness. Discount supermarkets, 'world', convenience and petrol stores all showed a varied distribution. ANOVA revealed evidence of a difference in healthfulness according to store type $(\mathrm{p}<0.001)$. Store type explained $53 \%$ of the variance of healthfulness. Adding neighbourhood deprivation quintiles to the model did not change the variance explained. Table 4 shows that the nine individual variables followed similar trends to the composite score across the seven different store types.

Figure 3 shows a tendency towards store healthfulness improving with increasing levels of neighbourhood affluence. However, the test for trend revealed that this association was not significant $(p=0.09)$. Examination of the relationship between individual components of the healthfulness score with neighbourhood deprivation highlighted several disparities (Table 5). Fresh produce quality declined as level of neighbourhood deprivation increased ( $<<0.01)$. The presence of nutrition information on less healthy items was greatest in the most affluent neighbourhoods while price promotions favoured less healthy products in all neighbourhoods except the most deprived (both $\mathrm{p}<0.01$ ). Prominent shelf and store placement of healthy products was slightly better in more affluent neighbourhoods ( $\mathrm{p}=0.04$ and $\mathrm{p}=0.05$ respectively) and the availability of healthier alternatives of less healthy foods was worst in the most deprived neighbourhoods $(\mathrm{p}=0.03)$. Product variety, price and single fruit sale were not associated with neighbourhood deprivation (all $\mathrm{p} \geq 0.3$ ).

\section{Discussion}

The composite score of healthfulness varied across different types of retail food stores. Similar trends were observed for the scores of the nine component variables (variety, price, quality, promotions, shelf placement, store placement, nutrition information, healthier alternatives and single fruit sale) across the seven store types. These findings suggest that the composite score provided good representation of the individual components. Large and premium supermarkets consistently offered environments that supported more healthful food choices and small supermarkets generally offered healthful environments. Discount supermarkets, convenience, 'world' and petrol stores offered less healthful environments. However, these store types had widely spread scores, indicating that there were examples of better practice for each of these less healthful store types. 


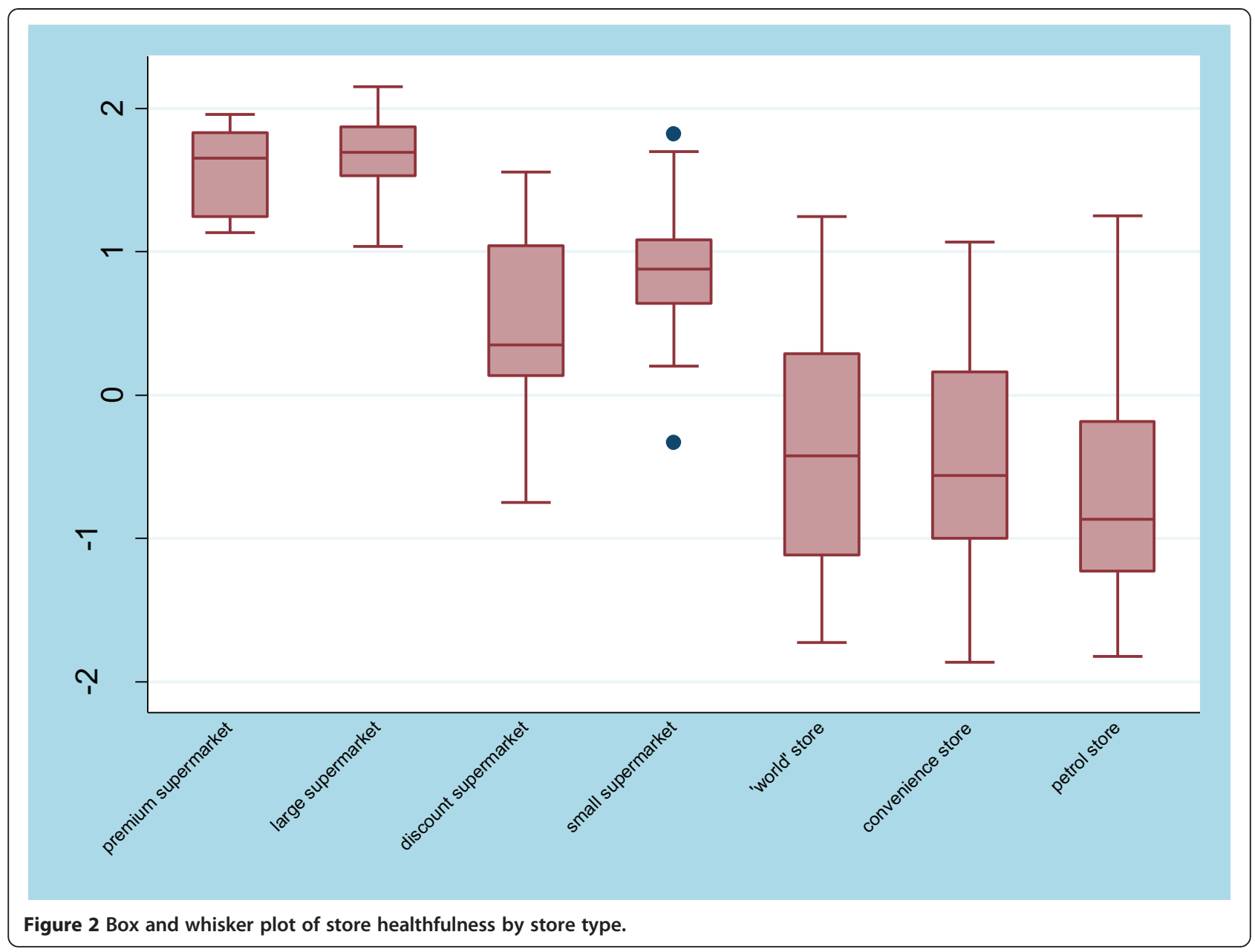

Level of neighbourhood deprivation did not predict store healthfulness. However, there was a trend towards affluent neighbourhoods having in-store environments more supportive of healthful food choices. The trends observed across the nine individual variable scores showed some disparities. Strong associations were observed for better quality produce and nutrition information in more affluent neighbourhoods, but unexpectedly, strong associations for healthier price promotion practices in the most deprived neighbourhoods. Weaker associations were found for poorer placement of healthy items and poorer availability of healthier alternatives in more disadvantaged neighbourhoods. No neighbourhood disparities were identified for product variety, price or single fruit sale. These results show how the composite score averages several multi-directional trends across the individual components. The healthfulness score also showed high internal $(\alpha=0.86)[12]$ consistency which indicates that the components measure one internally consistent underlying construct.

Our finding that large and premium supermarkets offered environments that support consumers choosing healthful foods is consistent with previous research $[11,37,38]$. Unlike previous research [39-41], store size did not necessarily determine overall store healthfulness. Smaller versions of large supermarkets offered more healthful shopping environments than bigger discount supermarkets. Discount supermarkets offered the least supportive environment for healthy eating of all supermarkets in our study with the median composite score for discount supermarkets considerably (0.6 SD) lower than other supermarkets. Previous research in England has shown poorer quality and availability of healthy foods in discount supermarkets [42]. However, research from Scotland revealed better availability of healthy foods in discount stores and cheaper prices [43]. Our analysis of the component variables revealed that discount supermarkets had more varieties of less healthy than healthy products, promoted less healthy products more than healthy products and had fewer healthier alternatives of less healthy foods than other supermarkets. These findings suggest that discount supermarkets may be a site for future intervention, particularly for researchers or policy makers addressing health inequalities. 
Table 4 Individual variable and composite scores by store type

\begin{tabular}{|c|c|c|c|c|c|c|c|c|c|c|}
\hline \multirow[b]{2}{*}{ Variable } & \multirow[t]{2}{*}{$\begin{array}{l}\text { Premium } \\
\text { supermarket }\end{array}$} & \multirow[t]{2}{*}{ Large supermarket } & \multirow{2}{*}{$\begin{array}{l}\text { Discount } \\
\text { supermarket }\end{array}$} & \multirow{2}{*}{$\begin{array}{l}\text { Small supermarket } \\
\text { Median }(I Q R)^{d}\end{array}$} & \multirow[t]{2}{*}{$\begin{array}{l}\text { 'World' } \\
\text { store }\end{array}$} & \multirow[t]{2}{*}{$\begin{array}{l}\text { Convenience } \\
\text { store }\end{array}$} & \multirow[t]{2}{*}{$\begin{array}{l}\text { Petrol } \\
\text { store }\end{array}$} & \multicolumn{2}{|c|}{$\begin{array}{c}\text { Possible } \\
\text { range }^{f}\end{array}$} & \multirow[b]{2}{*}{$p$-value } \\
\hline & & & & & & & & $\overline{M i n}$ & $\overline{M a x}$ & \\
\hline \multirow{2}{*}{$\begin{array}{l}\text { Composite } \\
\text { score }\end{array}$} & 1.7 & 1.7 & 0.3 & 0.9 & -.04 & -0.6 & -0.9 & -1.9 & 2.2 & $<0.001^{a}$ \\
\hline & (1.2 to 1.8$)$ & (1.5 to 1.9$)$ & (0.1 to 1.0$)$ & (0.6 to 1.1$)$ & $(-1.1$ to 0.3$)$ & $(-1.0$ to 0.2$)$ & $(-1.2$ to -0.2$)$ & & & \\
\hline \multirow[t]{2}{*}{ Variety } & 8 & 8 & -8 & -6 & -2 & -9 & -7 & -25 & 35 & $<0.001^{\mathrm{a}}$ \\
\hline & (7 to 8$)$ & (6 to 9 ) & $(-10$ to 1$)$ & $(-8$ to -2$)$ & $(-5$ to 0$)$ & $(-11$ to -7$)$ & $(-8$ to -5$)$ & & & \\
\hline \multirow[t]{2}{*}{ Price } & 0.03 & -0.03 & -0.01 & 0.02 & 0.04 & 0.03 & 0.02 & \multirow{2}{*}{\multicolumn{2}{|c|}{$\begin{array}{l}\text { Higher score } \\
\text { is more } \\
\text { healthful }\end{array}$}} & $0.002^{\mathrm{a}}$ \\
\hline & (0 to 0.05$)$ & $(-0.04$ to -0.01$)$ & $(-0.04$ to 0.01$)$ & (0.01 to 0.05 ) & $(-0.12$ to 0.1$)$ & $(-0.06$ to 0.08$)$ & $(-0.21$ to 0.1$)$ & & & \\
\hline \multirow[t]{2}{*}{ Promotions } & 0.5 & 0 & -1 & -1 & 0 & -1 & -1 & -5 & 7 & $<0.001^{a}$ \\
\hline & $(-1$ to 1$)$ & $(-1$ to 1$)$ & $(-3$ to 0$)$ & $(-2$ to -1$)$ & $(-0.4$ to 0$)$ & $(-1$ to 0$)$ & $(-1$ to 0$)$ & & & \\
\hline \multirow[t]{2}{*}{ Shelf placement } & 5 & 7 & 7 & 5 & 0 & -3 & -5 & -15 & 21 & $<0.001^{a}$ \\
\hline & (4 to 7 ) & (5 to 9$)$ & (4 to 9 ) & (4 to 7 ) & $(-3$ to 4$)$ & (-6 to 3) & $(-6$ to 1$)$ & & & \\
\hline \multirow[t]{2}{*}{ Store placement } & 4 & 4 & 4 & 4 & 1 & -4 & -4 & -15 & 21 & $<0.001^{\mathrm{a}}$ \\
\hline & (4 to 5) & (4 to 5 ) & (3 to 5) & (3 to 4) & $(-4$ to 5$)$ & (-6 to 2) & (-6 to 1) & & & \\
\hline \multirow[t]{2}{*}{ Quality } & 17 & 17 & 17 & 17 & 5 & 5 & 0 & 0 & 18 & $<0.001^{\mathrm{b}}$ \\
\hline & (17 to 17 ) & (16 to 18 ) & (15 to 18 ) & (15 to 17$)$ & (0 to 10$)$ & (0 to 13 ) & (0 to 8 ) & & & \\
\hline \multirow{2}{*}{$\begin{array}{l}\text { Healthier } \\
\text { alternative }\end{array}$} & 4 & 5 & 2 & 3 & 0 & 1 & 1 & 0 & 5 & $<0.001^{b}$ \\
\hline & (4 to 5) & (5 to 5) & (2 to 3 ) & (2 to 3 ) & (0 to 1) & (1 to 2 ) & (0 to 2) & & & \\
\hline \multirow{2}{*}{$\begin{array}{l}\text { Nutrition } \\
\text { information }\end{array}$} & 13 & 14 & 13 & 15 & 4 & 11 & 9 & 0 & 15 & $<0.001^{b}$ \\
\hline & (10 to 13 ) & (12 to 15$)$ & (13 to 14 ) & (15 to 15$)$ & (2 to 7 ) & (9 to 13 ) & (9 to 12 ) & & & \\
\hline $\begin{array}{l}\text { Single sale of } \\
\text { two fruits }^{\mathrm{e}}\end{array}$ & $100 \%$ & $97 \%$ & $26 \%$ & $87 \%$ & $23 \%$ & $19 \%$ & $21 \%$ & 0 & 2 & $<0.001^{c}$ \\
\hline
\end{tabular}

${ }^{a}$ Oneway analysis of variance, ${ }^{b}$ Kruskal-Wallis test, ${ }^{c}$ Chi square test, ${ }^{d}$ Median and inter-quartile range (IQR) were provided for both parametric and non-parametric

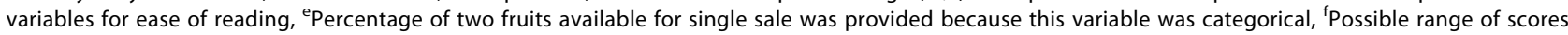
for each variable except composite score which shows actual range of composite score values.

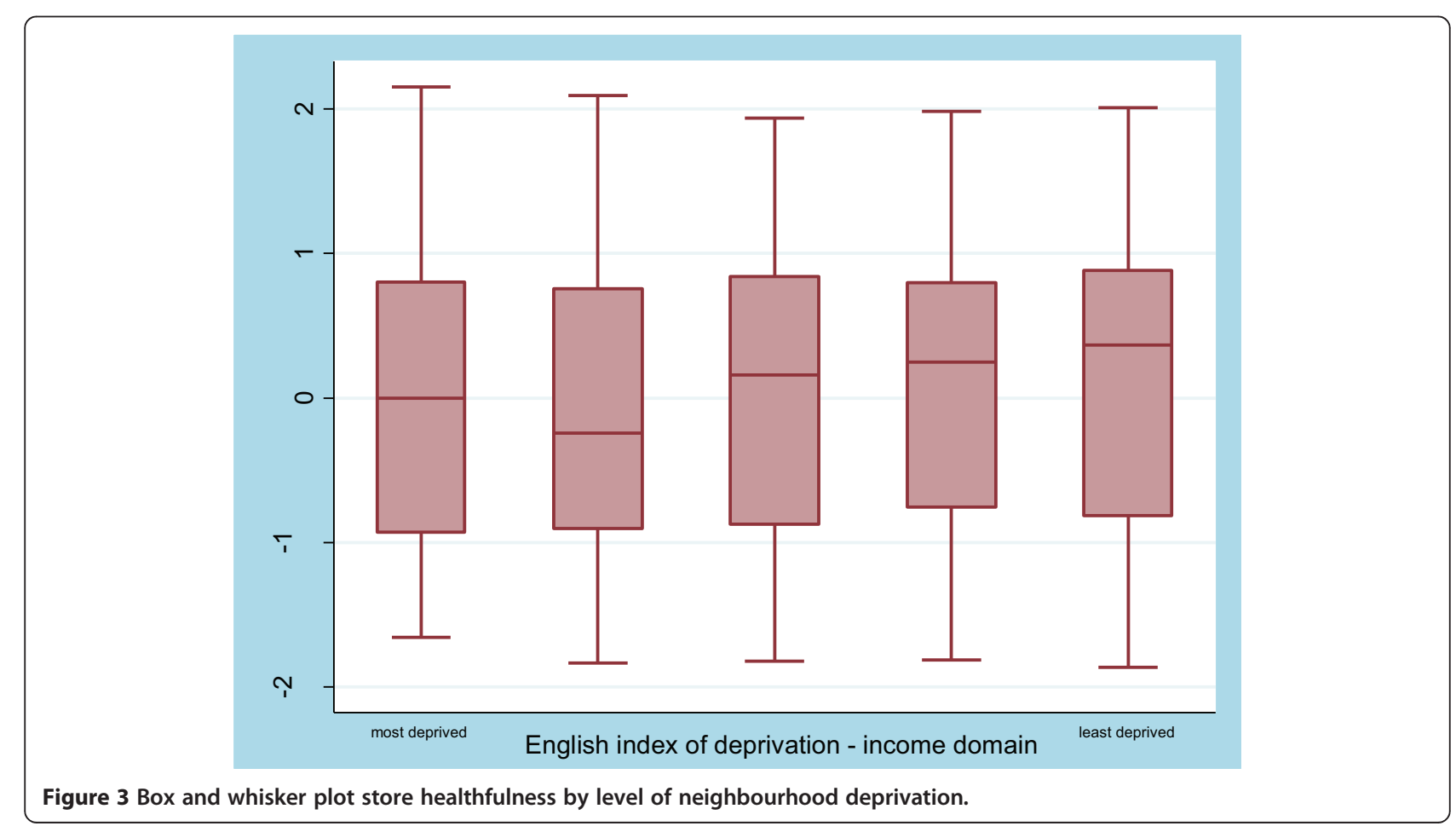


Table 5 Individual variable and composite scores by neighbourhood deprivation

\begin{tabular}{|c|c|c|c|c|c|c|c|c|}
\hline \multirow[b]{2}{*}{ Variable } & \multirow[t]{2}{*}{ Most deprived } & \multirow[t]{2}{*}{2} & \multirow{2}{*}{$\begin{array}{l}3 \\
\text { Median }(I Q R)^{c}\end{array}$} & \multirow[t]{2}{*}{4} & \multirow[t]{2}{*}{ Least deprived } & \multicolumn{2}{|c|}{ Possible range } & \multirow[b]{2}{*}{$p$-value } \\
\hline & & & & & & Min & Max & \\
\hline \multirow[t]{2}{*}{ Composite score } & 0 & -0.2 & 0.2 & 0.2 & 0.4 & -1.9 & 2.2 & $0.09^{\mathrm{a}}$ \\
\hline & (-0.9 to 0.8$)$ & (-0.9 to 0.8$)$ & $(-0.9$ to 0.8$)$ & $(-0.7$ to 0.8$)$ & $(-0.8$ to 0.9$)$ & & & \\
\hline \multirow[t]{2}{*}{ Variety } & -7 & -7 & -7 & -7 & -7 & -25 & 35 & $0.6^{a}$ \\
\hline & $(-9$ to -2.5$)$ & $(-10$ to -2$)$ & $(-9$ to -2$)$ & $(-8$ to -4$)$ & $(-10$ to -3$)$ & & & \\
\hline \multirow[t]{2}{*}{ Price } & 0.02 & 0.03 & 0.02 & 0.03 & 0.02 & Higher scor & e healthful & $0.5^{\mathrm{a}}$ \\
\hline & $(-0.04$ to 0.06$)$ & $(-0.05$ to 0.08$)$ & $(-0.04$ to 0.06$)$ & (-0.01 to 0.06$)$ & (-0.01 to 0.06$)$ & & & \\
\hline \multirow[t]{2}{*}{ Promotions } & 0 & -1 & -1 & -1 & -1 & -5 & 7 & $<0.001^{\mathrm{a}}$ \\
\hline & $(-1$ to 0$)$ & $(-1$ to 0$)$ & $(-1$ to 0$)$ & $(-2$ to 0$)$ & $(-2$ to 0$)$ & & & \\
\hline \multirow[t]{2}{*}{ Shelf placement } & 2 & 0 & 3 & 3 & 4 & -15 & 21 & $0.04^{\mathrm{a}}$ \\
\hline & $(-5$ to 7$)$ & $(-5$ to 5$)$ & $(-4$ to 6$)$ & $(-3$ to 6$)$ & $(-3$ to 6$)$ & & & \\
\hline \multirow[t]{2}{*}{ Store placement } & 1 & 0 & 2 & 2 & 2 & -15 & 21 & $0.05^{\mathrm{a}}$ \\
\hline & (-5 to 4$)$ & $(-5$ to 4$)$ & $(-4$ to 4$)$ & $(-4$ to 4$)$ & (-4 to 4$)$ & & & \\
\hline \multirow[t]{2}{*}{ Quality } & 9 & 8 & 13 & 12 & 14 & 0 & 18 & $0.002^{\mathrm{a}}$ \\
\hline & (1 to 15$)$ & (0 to 15$)$ & (3 to 17 ) & (0 to 17$)$ & (3 to 17 ) & & & \\
\hline \multirow[t]{2}{*}{ Healthier alternative } & 1 & 2 & 2 & 2 & 2 & 0 & 5 & $0.03^{\mathrm{a}}$ \\
\hline & (1 to 2 ) & (1 to 3 ) & (1 to 3 ) & (1 to 3 ) & (1 to 3 ) & & & \\
\hline \multirow[t]{2}{*}{ Nutrition information } & 12 & 12 & 12 & 12 & 13 & 0 & 15 & $0.003^{\mathrm{a}}$ \\
\hline & (9 to 14 ) & (9 to 14 ) & (9 to 14 ) & (10 to 15$)$ & (11 to 15$)$ & & & \\
\hline Single sale of two fruits ${ }^{d}$ & $42 \%$ & $36 \%$ & $39 \%$ & $43 \%$ & $43 \%$ & 0 & 2 & $0.4^{\mathrm{b}}$ \\
\hline
\end{tabular}

The healthfulness score we developed to measure overall in-store environment demonstrated the ability to discriminate within store types as well as between. For example, stores that are generally classified as 'unhealthy', such as petrol and convenience stores [44,45], revealed a spread in healthfulness scores from poor to good. This finding indicates there are examples of better, more healthful practices within less healthy store types and may also identify further subgroup categorisation of stores [46]. Further exploration of the specific differences and characteristics behind the better practices of more healthful stores may inform future store categorisation or identify targets for interventions to improve the environment of the least healthful food stores. Examples of successful initiatives to improve retail food stores exist [47], with interventions using multi-pronged strategies proving particularly effective [48]. Our composite measure of store healthfulness may provide a useful evaluation tool for future interventions addressing multiple in-store variables. In particular, the parametric nature of the healthfulness score provides more flexibility in statistical analyses than skewed measures.

Our results showed a trend for poorer store healthfulness in more deprived neighbourhoods however, this trend was not significant. Whilst no prior research has measured the full range of consumer nutrition environment factors included in this study, investigations in Scotland, England and Australia have shown little variation in availability and price by area level deprivation [49-51]. There are some illustrations in these countries for poorer fruit and vegetable quality $[18,52]$ and greater promotion of less healthy products [21] in retailers located in more deprived areas however research is limited. In the US disparities in availability, price, variety and quality of healthy food exist and favour more affluent, predominantly white neighbourhoods $[37,53]$. More frequent prominent placement of less healthy items in poorer Latino areas compared with wealthier white areas has been observed but the findings were not significant [19]. Country differences may be due to the higher levels of urban residential segregation in the US than in countries such as Australia and the UK [54]. The geography of food retailing may also differ across countries. In the UK for example, over the last two decades major retailers have adopted an urban regeneration agenda locating large stores on the periphery of towns [55] as well as opening smaller stores in city and town centres $[9,10]$. These supermarket developments 
may have addressed some of the socioeconomic disparities in food access in the UK.

\section{Strengths and limitations}

This study is the first to develop an overall measure of the consumer nutrition environment combining nine different variables into a single standardised score. The composite score characterised multiple environmental factors independent of measurement type; categorical, dichotomous and continuous measures were all represented equally in an overall score that was normally distributed. Using a standardised score provides a robust measure to conduct and interpret analyses and could ease examination of environmental and health/behavioural associations. The foods selected in this study are items which account for the most variance in tools used to discriminate between better and poorer dietary patterns in young women, young children and older adults. This selection could enable assessment of the relationship between environmental attributes of foods directly measured during dietary assessments in various populations in future research.

This study measured a much larger sample of stores than previous work $[13,16,20]$ and covered $99 \%$ of retail food stores in the study area. This coverage provides a thorough representation of the variation of healthfulness of retail food stores and enhances confidence in the accuracy of the study results.

Good to excellent kappa statistics (0.73-0.95) were returned for almost all variables. These results are similar to other in-store audit tools (kappa $>0.70$ ) [56]. The sample of stores included in this reliability test however was small $(\mathrm{n}=14)$ compared to similar studies $(\mathrm{n}=30$ to 85 ) $[13,17,19]$. The reliability (kappa 0.60 ) for fruit and vegetable quality was higher than the results reported in some studies [17], but lower than the results of others [57]. Future work using photos or a simple two-point scale of acceptable/unacceptable can provide a more consistent measure of quality as has been used in previous work $[17,58]$. Convergent validity against an alternative observational tool was not tested due to the intensive resources required for in-store audits. Data were collected from all store types and levels of neighbourhood deprivation over eleven months. Some aspects of seasonality or small price fluctuations may be been accounted for however, test-retest reliability and stability of items over time were not measured.

While our study was novel in assessing nine different in-store variables, three variables were restricted in their assessment. Shelf placement, store placement and nutrition information were all measured on the cheapest item available for each product category assessed. This restriction may have missed the opportunity to appropriately score the location of heavily promoted less healthy branded products, particularly in supermarkets which sell own-brand products. Other studies have assessed a specific brand and size of product [59] however, this approach is limited if not all stores stock that particular brand and size. For feasibility reasons specialty stores and restaurants were excluded. This study also has cross sectional and ecological limitations and the relationship between store healthfulness and diet was not assessed.

\section{Conclusion}

This study used a large sample of retail food stores $(n=601)$ to develop a composite measure of the consumer nutrition environment incorporating nine different variables. The composite score showed good internal consistency and represented overall trends of the individual variables across seven different store types and five levels of neighbourhood deprivation. The composite measure showed differences between and within store types identifying opportunities for intervention in discount supermarkets and other store types with environments less supportive of healthful food choices. The standardised composite score developed in this study can offer greater flexibility in statistical analyses of environment-diet relationships in future observational and interventions studies than single in-store measures, which can be skewed. The products included in this tool relate to dietary quality measures, thus this tool can be used to examine relationships between environmental attributes of foods directly measured during dietary assessments in various populations in future research.

\section{Additional file}

Additional file 1: Consumer nutrition environment audit tool and survey protocol.

\section{Competing interests}

Christina Black, Georgia Ntani, Hazel Inskip, Steve Cummins, Graham Moon and Janis Baird have no competing interests to declare and no financial disclosures to make.

Cyrus Cooper has no conflicts of interest to declare and has received consultancy, lecture fees and honoraria from AMGEN, GSK, Alliance for Better Bone Health, MSD, Eli Lilly, Pfizer, Novartis, Servier, Medtronic and Roche.

\section{Authors' contributions}

CB and JB conceived of the study, designed the audit tool, coordinated the data collection, healthfulness score development and analyses, and wrote the first draft of the manuscript. GN and HMI contributed to the development of the healthfulness score and performed the statistical analyses. CC, SC and GM participated in the design of the study and helped to draft the manuscript. All authors read and approved the manuscript.

\section{Acknowledgements}

Christina Black is supported by a United Kingdom National Institute for Health Research (NIHR) Doctoral Research Fellowship. Steve Cummins is supported by a United Kingdom NIHR Senior Fellowship. This project was supported by the United Kingdom Medical Research Council and the NIHR Nutrition Biomedical Research Centre, University of Southampton. The views expressed in this publication are those of the author(s) and not necessarily those of the NHS, the NIHR or the Department of Health. 
We are grateful to the managers of the retail food stores we visited, to Jamie Lawrence for assistance with data collection and Patsy Coakley for computing support.

\section{Funding sources}

This research and the authors of this paper are supported by the following funding sources: United Kingdom NIHR fellowships, United Kingdom Medical Research Council and the NIHR Nutrition Biomedical Research Centre, University of Southampton.

\section{Author details}

${ }^{1}$ Medical Research Council Lifecourse Epidemiology Unit, University of Southampton, Southampton General Hospital Tremona Road, Southampton SO16 6YD, United Kingdom. ${ }^{2}$ NIHR Nutrition Biomedical Research Centre, University of Southampton, Southampton SO16 6YD, United Kingdom. ${ }^{3}$ Department of Social and Environmental Health Research, Faculty of Public Health \& Policy, London School of Hygiene \& Tropical Medicine, 15-17 Tavistock Place, London WC9H 1SH, United Kingdom. ${ }^{4}$ Geography and Environment, University of Southampton, University Road, Southampton SO17 1BJ, United Kingdom.

Received: 21 October 2013 Accepted: 13 May 2014

Published: 23 May 2014

\section{References}

1. Caspi CE, Sorensen G, Subramanian SV, Kawachi I: The local food environment and diet: A systematic review. Health Place 2012, 18(5):1172-1187.

2. Holsten JE: Obesity and the community food environment: a systematic review. Public Health Nutr 2009, 12(3):397-405.

3. Cawley J, Meyerhoefer C: The medical care costs of obesity: an instrumental variables approach. J Health Econ 2012, 31(1):219-230

4. Department of Health UK: Reducing Obesity and Improving Diet. 2013. https://www.gov.uk/government/policies/reducing-obesity-and-improvingdiet and the date accessed was 06/10/2013.

5. Department of Health UK: Healthy Lives, Healthy People: Our Strategy for Public Health in England. London: Her Majesty's Stationery Office; 2010.

6. US National Institutes of Health: Strategic Plan for NIH Obesity Research. Washington DC: US Department of Health and Human Services; 2011.

7. Glanz K, Sallis JF, Saelens BE, Frank LD: Healthy Nutrition Environments: Concepts and Measures. Am J Health Promot 2005, 19(5):330-333.

8. Thornton LE, Kavanagh AM: Understanding the Local Food Environment and Obesity. In Geographies of obesity environmental understandings of the obesity epidemic. Edited by Pearce J, Witten K. Farnham, Ashgate: Ashgate's geographies of health series; 2010.

9. Clarke I, Hallsworth A, Jackson P, de Kervenoael R, del Aguila RP, Kirkup M: Retail restructuring and consumer choice 1 . Long-term local changes in consumer behaviour: Portsmouth, 1980-2002. Environ Plan A 2006, 38(1):25-46.

10. Hawkes C: Dietary implications of supermarket development: a global perspective. Dev Policy Rev 2008, 26(6):657-692.

11. Gustafson A, Hankins S, Jilcott S: Measures of the consumer food store environment: a systematic review of the evidence 2000-2011. J Community Health 2012, 37(4):897-911.

12. Ohri-Vachaspati $P$, Leviton LC: Measuring food environments: a guide to available instruments. Am J Health Promot 2010, 24(6):410-426.

13. Rimkus L, Powell LM, Zenk SN, Han E, Ohri-Vachaspati P, Pugach O, Barker DC, Resnick EA, Quinn CM, Myllyluoma J, Chaloupka FJ: Development and reliability testing of a food store observation form. J Nutr Educ Behav 2013, 45(6):540-548.

14. McKinnon RA, Reedy J, Morrissette MA, Lytle LA, Yaroch AL: Measures of the food environment: a compilation of the literature, 1990-2007. Am J Prev Med 2009, 36(4 Suppl):S124-S133.

15. Anderson A, Dewar J, Marshall D, Cummins S, Taylor M, Dawson J, Sparks L: The development of a healthy eating indicator shopping basket tool (HEISB) for use in food access studies-identification of key food items. Public Health Nutr 2007, 10(12):1440-1447.

16. Ball K, Timperio A, Crawford D: Neighbourhood socioeconomic inequalities in food access and affordability. Health Place 2009, 15(2):578-585.

17. Glanz K, Sallis JF, Saelens BE, Frank LD: Nutrition environment measures survey in stores (NEMS-S): development and evaluation. Am J Prev Med 2007, 32(4):282-289.
18. Cummins S, Smith DM, Taylor M, Dawson J, Marshall D, Sparks L, Anderson AS: Variations in fresh fruit and vegetable quality by store type, urban-rural setting and neighbourhood deprivation in Scotland. Public Health Nutr 2009, 12(11):2044-2050.

19. Kerr J, Sallis JF, Bromby E, Glanz K: Assessing reliability and validity of the GroPromo audit tool for evaluation of grocery store marketing and promotional environments. J Nutr Educ Behav 2012, 44(6):597-603.

20. Ghirardelli A, Quinn V, Sugerman S: Reliability of a retail food store survey and development of an accompanying retail scoring system to communicate survey findings and identify vendors for healthful food and marketing initiatives. J Nutr Educ Behav 2011, 43(4 Suppl 2):S104-S112.

21. Dibb, Sue and National Consumer Council: Healthy competition: how supermarkets can affect your chances of a healthy diet. London: National Consumer Council; 2005.

22. Morland K, Wing S, Roux AD: The contextual effect of the local food environment on residents' diets: The atherosclerosis risk in communities study. Am J Public Health 2002, 92(11):1761-1767.

23. Chung C, Myers S: Do the Poor Pay More for Food? An Analysis of Grocery Store Availability and Food Price Disparities. J Consum Aff 1999, 33(2):276-296. Blackwell Publishing Ltd.

24. Leibtag $\mathrm{E}$ : Where you shop matters: store formats drive variation in retail food prices. Amber Waves 2005:13-18.

25. Beaulac J, Kristjansson E, Cummins S: A systematic review of food deserts, 1966-2007. Prev Chronic Dis 2009, 6(3):A105

26. Black C, Moon G, Baird J: Dietary inequalities: What is the evidence for the effect of the neighbourhood food environment? Health Place 2013, 17:10.

27. Food Standards Agency: National Diet and Nutrition Survey 2000: adults consumption data. London: Food Standards Agency; 2009.

28. Robinson S, Syddall H, Jameson K, Batelaan S, Martin H, Dennison EM, Cooper C, Sayer AA: Current patterns of diet in community-dwelling older men and women: results from the Hertfordshire Cohort Study. Age Ageing 2009, 38(5):594-599.

29. Crozier SR, Inskip HM, Barker ME, Lawrence WT, Cooper C, Robinson SM: Development of a 20-item food frequency questionnaire to assess a 'prudent' dietary pattern among young women in Southampton. Eur J Clin Nutr 2010, 64(1):99-104.

30. Fisk CM, Crozier SR, Inskip HM, Godfrey KM, Cooper C, Robinson SM: Influences on the quality of young children's diets: the importance of maternal food choices. Br J Nutr 2011, 105(2):287-296.

31. Crozier SR, Inskip HM, Godfrey KM, Robinson SM: Dietary patterns in pregnant women: a comparison of food-frequency questionnaires and 4 d prospective diaries. Br J Nutr 2008, 99(4):869-875.

32. Mills, Alison, Patel, Sejal, Great, Britain, Ministry of Agriculture, Fisheries and Food, and Crawley, Helen: Food portion sizes. 2nd edition. London: HMSO; 1993.

33. Food Standards Agency: Guidance for food hygiene and food standards premises. 2010. http://www.food.gov.uk/enforcement/auditandmonitoring/ laems/definitions/ and the date accessed was 25/03/2010

34. Lake AA, Burgoine T, Greenhalgh F, Stamp E, Tyrrell R: The foodscape: classification and field validation of secondary data sources. Health Place 2010, 16(4):666-673.

35. Noble M, McLennan D, Wilkinson $K$, Whitworth A, Barnes H, Dibben C: English Indices of Deprivation 2007. London: Communities and Local Government; 2008.

36. Office for National Statistics: Rural/Urban definition (England and Wales). Office for National Statistics; 2005. https://www.gov.uk/government/ collections/rural-urban-definition and the date accessed was 07/05/2011.

37. Larson NI, Story MT, Nelson MC: Neighborhood environments: disparities in access to healthy foods in the U.S. Am J Prev Med 2009, 36(1):74-81.

38. Dawson J, Marshall D, Taylor M, Cummins S, Sparks L, Anderson AS: Accessing healthy food: availability and price of a healthy food basket in Scotland. J Mark Manag 2008, 24(9):893-913. Routledge.

39. Latham J, Moffat T: Determinants of variation in food cost and availability in two socioeconomically contrasting neighbourhoods of Hamilton, Ontario, Canada. Health Place 2007, 13(1):273-287.

40. Guy CM, David G: Measuring physical access to healthy foods in areas of social deprivation: a case study in Cardiff. Int J Consum Stud 2004, 28(3):222-234. Blackwell Science Ltd.

41. Block D, Kouba J: A comparison of the availability and affordability of a market basket in two communities in the Chicago area. Public Health Nutr 2006, 9(7):837-845

42. White M, Bunting J, Williams L, Raybould S, Adamson A, Mathers J: Do 'food deserts' Exist? A Multi-Level, Geographical Analysis of the Relationship Between 
Retail Food Access, Socio-Economic Position and Dietary Intake. Newcastle Tyne: Food Standards Agency; 2004.

43. Cummins S, Macintyre S: A systematic study of an urban foodscape: The price and availability of food in Greater Glasgow. Urban Stud 2002, 39(11):2115-2130

44. Pearce J, Hiscock R, Blakely T, Witten K: The contextual effects of neighbourhood access to supermarkets and convenience stores on individual fruit and vegetable consumption. J Epidemiol Community Health 2008, 62(3):198-201.

45. Morland K, Diez Roux AV, Wing S: Supermarkets, other food stores, and obesity: the atherosclerosis risk in communities study. Am J Prev Med 2006, 30(4):333-339.

46. IGD: global food and consumer goods experts. Symbol Groups Market Overview 2012, 9:8. 11-7-2013.

47. Department of Health UK: Change4Life Convenience Stores Evaluation Report. London: Her Majesty's Stationery Office; 2010.

48. Gittelsohn J, Rowan M, Gadhoke P: Interventions in small food stores to change the food environment, improve diet, and reduce risk of chronic disease. Prev Chronic Dis 2012, 9:E59.

49. Cummins S, Smith DM, Aitken Z, Dawson J, Marshall D, Sparks L, Anderson AS: Neighbourhood deprivation and the price and availability of fruit and vegetables in Scotland. J Hum Nutr Diet 2010, 23(5):494-501.

50. Giskes K, van Lenthe FJ, Brug J, Mackenbach JP, Turrell G: Socioeconomic inequalities in food purchasing: the contribution of respondent-perceived and actual (objectively measured) price and availability of foods. Prev Med 2007, 45(1):41-48.

51. Black C, Ntani G, Kenny R, Tinati T, Jarman M, Lawrence W, Barker M, Inskip H, Cooper C, Moon G, Baird J: Variety and quality of healthy foods differ according to neighbourhood deprivation. Health Place 2012, 18(6):1292-1299.

52. Millichamp A, Gallegos D: Comparing the availability, price, variety and quality of fruits and vegetables across retail outlets and by area-level socio-economic position. Public Health Nutr 2013, 16(1):171-178.

53. Walker RE, Keane CR, Burke JG: Disparities and access to healthy food in the United States: A review of food deserts literature. Health Place 2010 16(5):876-884.

54. Johnston R, Poulsen M, Forrest J: The geography of ethnic residential segregation: A comparative study of five countries. Ann Assoc Am Geogr 2007, 97(4):713-738.

55. Wrigley N, Guy C, Lowe M: Urban regeneration, social inclusion and large store development: The Seacroft development in context. Urban Stud 2002, 39(11):2101-2114.

56. Lytle LA: Measuring the food environment: state of the science. Am J Prev Med 2009, 36(4 Suppl):S134-S144.

57. Zenk SN, Lachance LL, Schulz AJ, Mentz G, Kannan S, Ridella W: Neighborhood retail food environment and fruit and vegetable intake in a multiethnic urban population. Am J Health Promot 2009, 23(4):255-264.

58. Minaker LM, Raine KD, Wild TC, Nykiforuk CIJ, Thompson ME, Frank LD: Objective food environments and health outcomes. Am J Prev Med 2013, 45(3):289-296.

59. Palermo C, Wilson A: Development of a healthy food basket for Victoria. Aust N Z J Public Health 2007, 31(4):360-363.

\section{doi:10.1186/1479-5868-11-69}

Cite this article as: Black et al:: Measuring the healthfulness of food retail stores: variations by store type and neighbourhood deprivation. International Journal of Behavioral Nutrition and Physical Activity 2014 11:69.

\section{Submit your next manuscript to BioMed Central and take full advantage of:}

- Convenient online submission

- Thorough peer review

- No space constraints or color figure charges

- Immediate publication on acceptance

- Inclusion in PubMed, CAS, Scopus and Google Scholar

- Research which is freely available for redistribution 